\title{
PRODUÇÃO ACADÊMICA SOBRE SUCESSÃO RURAL E AGRICULTURA FAMILIAR: UMA ANÁLISE DO CONTEXTO BRASILEIRO DO PERÍODO (2003-2018)
}

\author{
João Paulo Louzada Vieira ${ }^{1}$ \\ Douglas Vianna Bahiense ${ }^{2}$ \\ Suany Machado da Silva ${ }^{3}$
}

\begin{abstract}
RESUMO
Nos últimos anos, o Brasil tem institucionalizado uma série de políticas públicas e ações voltadas para o segmento da agricultura familiar. Nesse contexto, emerge a juventude rural como uma categoria de ator social responsável pela continuidade da propriedade familiar, que passa a ser valorizada pelas ações governamentais e pelos debates científicos. Considerando essa valorização, o presente artigo busca analisar os fatores que interferem no processo sucessório na agricultura familiar e como vem sendo trabalhado as políticas públicas para a juventude rural nas pesquisas científicas. Metodologicamente, optou-se por utilizar o estado da arte acerca do tema em estudo, tomando-se como corpus de análise à produção acadêmica no período de 2003 a 2018 disponível no Portal de Periódicos CAPES. Foi encontrado um total de 29 trabalhos científicos divididos em 3 principais áreas do conhecimento que analisam os processos socioculturais e econômicos da sucessão rural.
\end{abstract}

Palavras-chave: Juventude rural, transmissão geracional, estado da arte, projetos familiares de descolamentos.

\section{ACADEMIC PRODUCTION ON RURAL SUCCESSION AND FAMILY FARMING:AN ANALYSIS OF THE BRAZILIAN CONTEXT OF THE PERIOD (2003- 2018)}

\begin{abstract}
In the past few years, Brazil institucionaliazed a series of a public politics and actions to comeback to the segment of familiar agriculture. In this context, it brings the rural youth as a category of a new program social responsible for the continuing of familiar propriety, the rural youth has now worthy for the government actions and for cientific debates. Considering this appreciation, this article seeks analyze the factores that interfers in the proccess of succession in the familiar agriculture and how this is coming

\footnotetext{
${ }^{1}$ Graduado em Direito pela Faculdade de Ciências e Tecnologia de Viçosa (UNIVIÇOSA); Graduado em História pela Universidade Federal de Viçosa (UFV); Especialização em Direito Urbanístico e Ambiental pela Pontifícia Universidade Católica de Minas Gerais (PUC-MINAS); Mestre em Extensão Rural pela Universidade Federal de Viçosa (UFV); E-mail: joaopaulo.direito@yahoo.com.br;

${ }^{2}$ Graduado em Agronomia pela Universidade Federal do Espírito Santo (UFV); Mestre em Extensão Rural pela Universidade Estadual Norte Fluminense Darcy Ribeiro (UENF); E-mail: douglas.bahiense@yahoo.com.br

${ }^{3}$ Graduada em Agronomia pela Universidade Federal Rural da Amazônia (UFRA); Mestre em Extensão Rural pela Universidade Federal de Viçosa (UFV); E-mail: suanysilva@yahoo.com.br
} 
been working in the public politics to rural youth in the cientific research. Methodologically, we opted for use the state of art in the theme of this study, taking as corpus of analysis the academic production in the period from 2003 to 2018 , available at CAPES Periodic Portal. It was find a total of 29 cientific work divided in 3 principles áreas of knowledge that analysis the proccess sociocultures and economics of succession rural.

Palavras-chave: Youth Rural, generation transmission, state of art, family displacement projects.

\section{INTRODUÇÃO}

Atualmente a agricultura familiar é responsável por grande parte do abastecimento alimentar brasileiro, em que apresenta uma ampla exposição das variedades de produtos. Isso eleva a sua vantagem no processo de desenvolvimento econômico, principalmente no que diz respeito à permanência das famílias no meio rural e geração de renda no campo. Segundo o artigo 3ํ da Lei 11.326/2006, entendese por agricultor (a) familiar aquele que atende os seguintes requisitos:

i) não detenha propriedade com área superior a quatro módulos fiscais; ii) utiliza mão de obra familiar nas atividades econômicas do estabelecimento; iii) - tenha percentual mínimo da renda familiar originada de atividades econômicas do seu estabelecimento ou empreendimento, na forma definida pelo Poder Executivo; IV - dirija seu estabelecimento ou empreendimento com sua família (BRASIL, 2006).

Contudo, o seu conceito não se limita a perspectiva da legislação brasileira e, com isso, passa por diversas construções teóricas. Nesse sentido, acrescenta-se que é "o setor da agricultura em que os gerentes ou administradores dos estabelecimentos rurais são também os próprios trabalhadores rurais" (FLORES, 1998, p. 9).

Em uma abordagem temporal, Grisa e Schneider (2014) apontam que a agricultura familiar no Brasil passou por três importantes momentos (referencial global; referencial setorial e referencial de política pública), os quais contribuíram para que se tornassem reconhecidos. Essa conquista foi fundamental para o seu fortalecimento, que se deu pelo crescimento de políticas voltadas para esses agricultores.

Contudo, mesmo com o crescimento das políticas públicas voltadas para a agricultura familiar ${ }^{4}$, a migração rural ainda permanece como fonte de preocupação para os pequenos produtores inseridos nessa categoria, o que tem elevado o índice da descontinuidade da profissão, colaborando ainda com a saída de jovens do campo. A dificuldade para acessar recursos e as políticas públicas, a falta de tecnologia no processo produtivo, bem como a dependência econômica são fatores que têm motivado a juventude rural a buscar outros modos de vida e fontes de renda diversas, principalmente nos centros urbanos, deixando a propriedade sem que haja um sucessor.

Devido a isto, o envelhecimento da população rural insere os jovens no protagonismo de ações governamentais e nos debates científicos. A juventude rural é

\footnotetext{
${ }^{4}$ A agricultura familiar, reconhecida em meados da década de 1990 pelo Estado brasileiro, destaca-se como protagonista de muitas mudanças e passa a ser reconhecida como uma categoria sociopolítica. Dessa forma, passa a ser beneficiada com a construção de políticas públicas diferenciadas, o que até então não havia sido possível, pois estava à margem das ações do Estado, conforme explica Grisa e Schneider (2014).
} 
qualificada, portanto, como a responsável não somente pela gestão da propriedade, mas também pela manutenção de um modo de vida que é transmitido pelas gerações mais velhas (ABRAMOVAY 1998). Entretanto, estes sucessores muitas vezes se sentem desestimulados a continuarem os negócios familiares.

Pelas características da atividade laboral, sua manutenção é de fundamental importância para o cenário alimentar brasileiro. Neste sentido, a juventude rural destaca-se como ator responsável pela continuidade futura da propriedade e da reprodução social do modo de vida rural, exercendo seu protagonismo no desenvolvimento da unidade produtiva familiar. Entretanto, diversos fatores podem influenciar o processo sucessório, desestimulando ou não a permanência do jovem no campo.

O êxodo rural e migração são processos antigos no Brasil, principalmente em contextos de escassez de terras e dificuldade de reprodução social dos agricultores, que utilizam da migração sazonal como uma prática para a complementação da renda familiar. Tais processos foram observados principalmente no período da ditadura militar (1960-1985), sendo a principal queixa dos migrantes a falta ou a dificuldade ao acesso a políticas públicas para o desenvolvimento rural (CASTRO, 2009). Para Abramovay (1998), o que está em jogo no processo sucessório não é somente a reprodução da família dos agricultores em si, mas o futuro de algumas regiões que passam por severos processos de esvaziamento.

Com isso, entende-se por sucessão rural, processos sociais pelos quais passa uma nova geração de produtores (ABRAMOVAY, 1998). Nestes processos insere-se a sucessão profissional, a transferência hereditária da propriedade rural e a aposentadoria. No mesmo sentido, Stropasolas (2011, p. 26), acrescenta que é: "a transferência do poder e do patrimônio entre gerações no âmbito da produção agrícola familiar, a retirada paulatina das gerações mais idosas da gestão do estabelecimento e a formação profissional de um novo agricultor (a)".

Unindo os conceitos apresentados acima, temos uma categoria de análise apresentada neste trabalho, ou seja, a sucessão rural na agricultura familiar como pode ser observado:

A agricultura é uma ocupação que busca assegurar a continuidade patrimonial da família através da transmissão aos seus descendentes. A lógica da sucessão baseia-se na necessidade de manter o patrimônio familiar representado pela terra. Para manter assegurada essa lógica, os agricultores buscam entre seus filhos um sucessor para seu patrimônio" (SPANEVELLO, 2008, p.22).

Segundo Aquino e Schneider (2015), a agricultura familiar passou por momentos de marginalização no cenário brasileiro, principalmente por sua herança colonial e pela "modernização desigual" da agricultura nacional, implementada com mais rigidez a partir da segunda metade da década de 1960. Neste período houve uma intensificação da valorização de médios e grandes produtores através de políticas governamentais. A partir da década de 1980, retoma-se o debate acerca das reivindicações dos movimentos sociais do campo visando a recuperação dos efeitos negativos da política econômica vivenciada no período da ditadura militar.

No ano de 1990, inicia-se um período de formulação de políticas públicas objetivando atender as demandas dos agricultores familiares. Em 1996, foi criado o Programa Nacional de Fortalecimento da Agricultura Familiar - Pronaf, que busca combater as desigualdades sociais contribuindo para o desenvolvimento rural, 
financiando projetos que proporcionam renda aos agricultores familiares e assentados. Atualmente o programa consiste no financiamento de projetos individuais ou coletivos para agricultores familiares e assentamentos de reforma agrária, com taxa de juros efetivamente baixas, facilitando o acesso às linhas de créditos rurais. (BRASIL, 2017).

Ao longo dos anos, principalmente a partir do ano de 2004, é possível perceber os diversos programas governamentais direcionados a juventude rural (15 a 29 anos) implementando política públicas para a categoria. Diversas instituições pertencentes ao Estado iniciaram a discussão sobre o futuro do jovem pobre naquele período (CASTRO; BARCELLOS, 2015).

Ao longo dos anos foram formulados vários tipos de ações governamentais e não-governamentais que buscam a inserção da juventude rural no calendário das políticas públicas e na agenda social, principalmente desenvolvidas pelos estabelecimentos educacionais, movimentos religiosos, programas voltados para o esporte e criação de linhas de crédito bancárias.

Para Castro e Barcellos (2015), a partir da vigência do mandato do Governo Lula (2003-2010), com foco específico na juventude rural, as políticas públicas para a agricultura familiar passaram por uma reorientação e receberam grandes investimentos, objetivando atender as demandas dos agricultores familiares, assentamentos de reforma agrária, comunidades quilombolas, comunidades tradicionais, dentre outros.

O ano de 2004 aparece como um grande marco para o segmento juvenil, quando foram criados dois programas pelo Governo Federal: o "Pronaf Jovem", que tem por objetivo disponibilizar uma linha de crédito específica para os jovens desenvolverem suas próprias atividades econômicas e o Programa Nacional de Crédito Fundiário (PNCF) com a linha Nossa Primeira Terra (CASTRO; BARCELLOS, 2015).

Durante o Governo de Dilma Rousseff, foi sancionado o Decreto n 8.736, de 3 de maio de 2016, que institui o Plano Nacional de Juventude e Sucessão Rural no âmbito do Ministério do Desenvolvimento Agrário com objetivo de integrar e articular políticas através de programas e ações para a promoção da sucessão rural e a garantia dos direitos da juventude do campo (BRASIL, 2016).

Atualmente, pode-se dizer que a juventude rural alcançou um patamar de visibilidade social, embora ainda permaneçam vários problemas estruturais que dificultam o exercício pleno da cidadania, bem como o usufruto de direitos e o acesso a bens da modernidade. Essa visibilidade é resultante da maior participação pública, política e do aprofundamento de pesquisas científicas sobre o segmento juvenil rural. Acrescenta Stropasolas (2007), que até recentemente eram raros os estudos que abordavam essa categoria, especialmente os que residiam em pequenas localidades.

É importante destacar a inclusão das instituições parceiras nas políticas públicas e o papel das universidades, institutos, ONGs e movimentos sociais para a compreensão da vida desses jovens rurais, pois elas visam investigar os problemas enfrentados por esse segmento, buscando possíveis soluções para a permanência e continuidade das atividades econômicas (novas e tradicionais) do espaço rural. Para Brumer (2004) e Carneiro (2007), entre as principais demandas almejadas pela juventude rural são o acesso à informática no campo; a utilização de tecnologias no modo produtivo; a participação feminina no gerenciamento da propriedade; a realização de atividades menos desgastantes ou não agrícolas; acesso aos centros urbanos; e a abertura familiar para negociação da gestão da propriedade.

Kruger et al. (2018) identificaram os principais fatores decisivos nos processos de sucessão rural, sobretudo nos municípios do interior catarinense. Nos pontos positivos, os jovens indicam que a melhoria da renda da propriedade, 
oportunidade de crescimento profissional e apoio governamental na política de subsídios são fatores incentivadores ao ponto de permanecerem próximos à família. Nos pontos restritivos há devidas preocupações dos jovens por conta do tamanho da propriedade rural, baixa produtividade e rendimento e da falta de reconhecimento.

No trabalho desenvolvido por Gris, Lago e Brandalise (2017) referente ao tema de sucessão familiar na produção científica, também indica que diversos fatores contribuem para a falta de interesse do jovem em continuar no campo, como: 1) limitações de renda e do acesso a políticas públicas; 2) falta de organização no espaço rural;3) participação tardia dos jovens nas atividades de gestão rural; 4) risco de evasão escolar por conta da maior distância dos distritos rurais aos centros de ensino e a desigualdade de gênero.

Para Wanderley (2003), se atualmente o foco da discussão busca apresentar o significado da agricultura familiar neste novo contexto rural, é porque este outro modo social de produção ocupa um lugar importante no cenário atual da economia e da sociedade brasileira.

A partir dessas considerações iniciais, o presente trabalho tem por objetivo mapear a produção acadêmica científica referente ao processo de sucessão rural na agricultura familiar nos últimos quinze anos (2003 -2018). Por meio do Banco de Teses e Periódicos da Coordenação de Aperfeiçoamento de Pessoal de Nível Superior (CAPES), pretende-se com essa pesquisa averiguar se os trabalhos sobre sucessão rural na agricultura familiar abordam as políticas públicas para a juventude rural como um fator a influenciar a permanência do jovem no campo.

\section{METODOLOGIA}

Para alcançar os objetivos almejados optou-se por realizar um "estado da arte", que nos últimos anos, tanto no Brasil assim como em outros países, tem-se revelado como uma ferramenta auxiliar na categorização de pesquisas bibliográficas. Para Ferreira (2002, p. 257), esse tipo de pesquisa caracteriza-se como um "levantamento bibliográfico, objetivando a realização de um mapeamento sobre um determinado tema estudado na produção acadêmica em diferentes áreas do conhecimento". A sua contribuição é de fundamental importância para o meio acadêmico, pois apresenta quais dimensões vem sendo destacadas, bem como os pontos mais explorados nos estudos e, sobretudo, o formato em que estão sendo divulgadas tais pesquisas, por meio de dissertação, tese ou artigos científicos.

Realizou-se uma pesquisa no banco de Periódicos da Capes no período entre os anos de 2003 a 2018, onde foram encontradas 164 publicações entre artigos, resenhas e anais de congressos ${ }^{5}$ que mencionaram o tema em questão. Em seguida, depurou-se através das leituras dos títulos e resumos, as publicações compatíveis no termo da pesquisa e, por isso, do total de trabalhos encontrados, apenas 29 foram selecionados para a análise devido tratarem diretamente sobre o tema estudado. Cabe ressaltar que o termo de busca utilizado foi "sucessão rural na agricultura familiar".

Tabulação segundo Gil (2008), consiste no agrupamento e contagem dos casos que estão nas várias categorias de análises. Esta pesquisa buscou explorar o período da produção acadêmica; a área de concentração dos trabalhos; região; local de aplicação; atividades produtivas na agricultura familiar e questões de gênero. As discussões sobre os resultados se dão principalmente as condições favoráveis para a

\footnotetext{
${ }^{5}$ Neste trabalho não se fez a utilização de teses e dissertações referentes ao tema.
} 
permanência do jovem no campo e os fatores que ocasionam sua saída dos espaços rurais.

A importância desse estudo está na possibilidade de mensurar os índices de produção e disseminação científica sobre o processo sucessório na agricultura familiar, uma vez que estes vivenciam problemas de evasão ou falta de interesse da juventude rural em manter as atividades dos seus antecessores. Dessa forma, através do acompanhamento da produção científica, é possível verificar o padrão das publicações que estão sendo desenvolvidas, em determinadas bases de dados, sobre um tema específico e, compreender também, quais outros assuntos estão presentes ou que ainda merecem maior atenção em relação ao tema principal de sucessão rural na agricultura familiar.

\section{RESULTADOS E DISCUSSÃO}

A partir da investigação e depuração dos dados do banco de Periódicos da CAPES foi possível constatar que do total de 164 publicações ligadas ao tema, apenas 29 tratavam especificamente sobre a sucessão rural na agricultura familiar, sendo que 26 eram artigos científicos e 3 trabalhos eram de anais de congressos, o restante fazia uma menção simplória sobre o assunto, mas não estava diretamente relacionado.

Os trabalhos analisados distribuem-se por um recorte temporal entre os anos de 2003 a 2018, onde o ano de 2016 apresentou um maior número de publicações (seis) (Gráfico 1). O ano de 2003 foi utilizado como marco inicial dessa pesquisa por ser um período que houve uma intensificação das políticas públicas para a agricultura familiar e para a juventude rural no Brasil.

Entre os anos analisados foi possível perceber as oscilações dos trabalhos científicos publicados relacionados ao tema em estudo. Pode-se justificar tal situação pelo fato de que as políticas públicas direcionadas a agricultura familiar bem como para a juventude rural ainda eram recentes na pauta de discussão. Percebe-se ainda que nos anos de 2010, 2014 e 2017 houve um declínio drástico das pesquisas sobre o assunto.

Gráfico 1 - Recorte temporal das publicações científicas sobre Sucessão Rural na Agricultura Familiar.

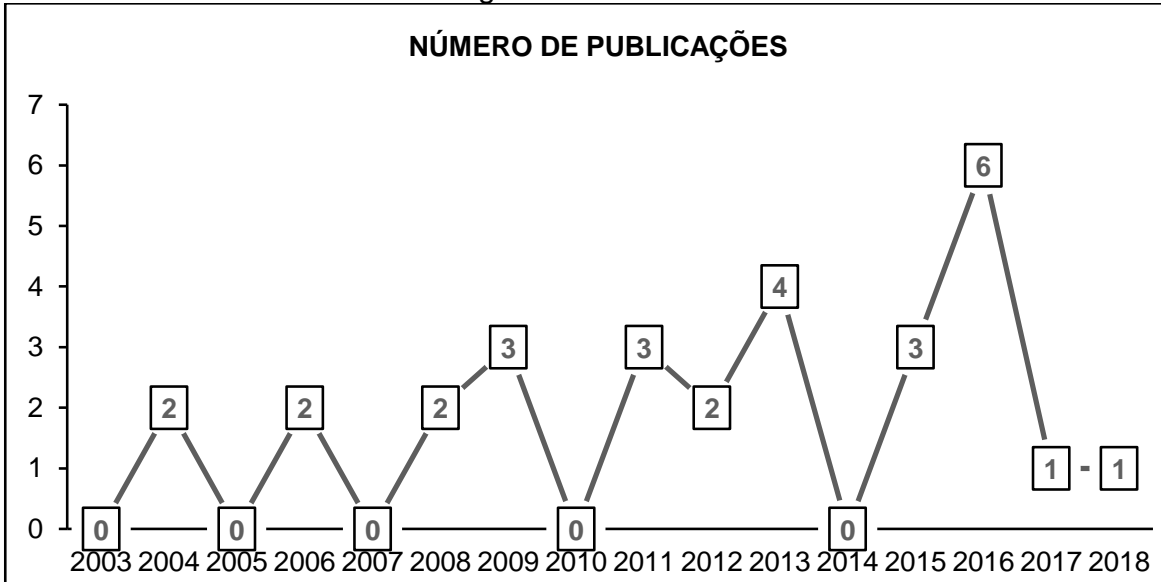

Fonte: Elaborado pelos autores a partir do Portal de Periódicos da CAPES - 2019. 
As publicações analisadas foram distribuídas em áreas específicas de acordo com a consulta dos periódicos registrados no Portal. Dentre essas áreas científicas, os resultados mostram que há maior abrangência nas Ciências Agrárias; Interdisciplinar; Ciências Sociais e Ciências Humanas, conforme a Tabela 1. Isso se justifica pelo fato de que os artigos enfatizaram o desenvolvimento do escopo das ciências agrárias e trabalham não somente com o setor produtivo, mas com o aspecto social na agricultura familiar. O mesmo ocorre com as demais áreas visando o desenvolvimento socioeconômico na maioria dos artigos.

A partir da análise dos resultados, pode-se afirmar que o processo de sucessão rural na agricultura familiar é interpretado em seus diversos ângulos a partir das áreas do conhecimento da pesquisa. Como exemplos, as "Ciências Sociais Aplicadas " e "Ciências Econômicas e Sociais" buscam no sentido geral o estudo do gerenciamento da propriedade, apontando características que favorecem a permanência do jovem no campo, como a implantação de atividades agroindustriais e também fatores que implicam as dúvidas dos próprios pais em darem condições de suceder as atividades agrícolas aos jovens.

Em relação aos programas voltadas para o campo social como Ciências Sociais, Ciências Humanas, Geografia, História, Inter e Multidisciplinares apresentaram em seus trabalhos acadêmicos que mesmo diante de tantas dificuldades, grande parte da juventude rural ainda permanece na zona rural pela importância de uma continuidade do modo de vida presente na propriedade e o legado familiar. Nos artigos publicados, destacaram-se os variados aspectos sociais da juventude no campo no Brasil.

Tabela 1 - Distribuição das grandes áreas de conhecimento dos periódicos.

\begin{tabular}{lr}
\hline \multicolumn{1}{c}{ ÁREA DE CONCENTRAÇÃO } & QUANTIDADE \\
\hline Ciências Agrárias & 9 \\
Interdisciplinar & 6 \\
Ciências Sociais & 5 \\
Ciências Humanas & 4 \\
Multidisciplinar & 3 \\
Geografia & 2 \\
Ciências Sociais Aplicadas & 2 \\
Ciências Econômicas e Sociais & 1 \\
História & 1 \\
\hline
\end{tabular}

Fonte: Elaborado pelos autores a partir do Portal de Periódicos da CAPES - 2019.

Ao realizar a distribuição dos trabalhos por regiões do Brasil, foi possível o mapeamento dos estados brasileiros em que se realizou as pesquisas sobre o tema e quais as Universidades, Faculdades e Institutos que foram desenvolvidas. A Região Sul aparece com um maior número de trabalhos produzidos frente as outras Regiões. Tal situação pode ser justificada pela alta concentração de programas de pósgraduação em desenvolvimento, sociologia e extensão rural na região, em que a linha da agricultura familiar é muito discutida. Em seguida, destaca-se a Região Sudeste, a Região Centro-Oeste e de Escopo Nacional, conforme a Tabela 2. 
Tabela 2 - Publicações da Sucessão Rural na Agricultura Familiar por Região.

\begin{tabular}{lr}
\hline Região Brasileira & Número de Publicações \\
\hline Região Sul & 17 \\
Região Sudeste & 4 \\
Região Centro-Oeste & 4 \\
Escopo Nacional & 4
\end{tabular}

Fonte: Elaborado pelos autores a partir do Portal de Periódicos da CAPES - 2019.

Pela análise das regiões, é possível ainda realizar a distribuição dos trabalhos pelos Estados de forma a especificar ainda mais a origem destas pesquisas. Pode-se perceber que o Estado do Rio Grande do Sul possui o maior número de publicações, contabilizando um total de onze pesquisas realizadas. Em seguida destacam-se Santa Catarina com o número total de cinco, e Escopo Nacional com quatro publicações. Os outros estados que aparecem nos dados contabilizam de $1 \mathrm{a}$ 3 artigos científicos produzidos (Gráfico 2).

Gráfico 2 - Relação dos Estados com maior número de artigos sobre Sucessão Rural na agricultura familiar.

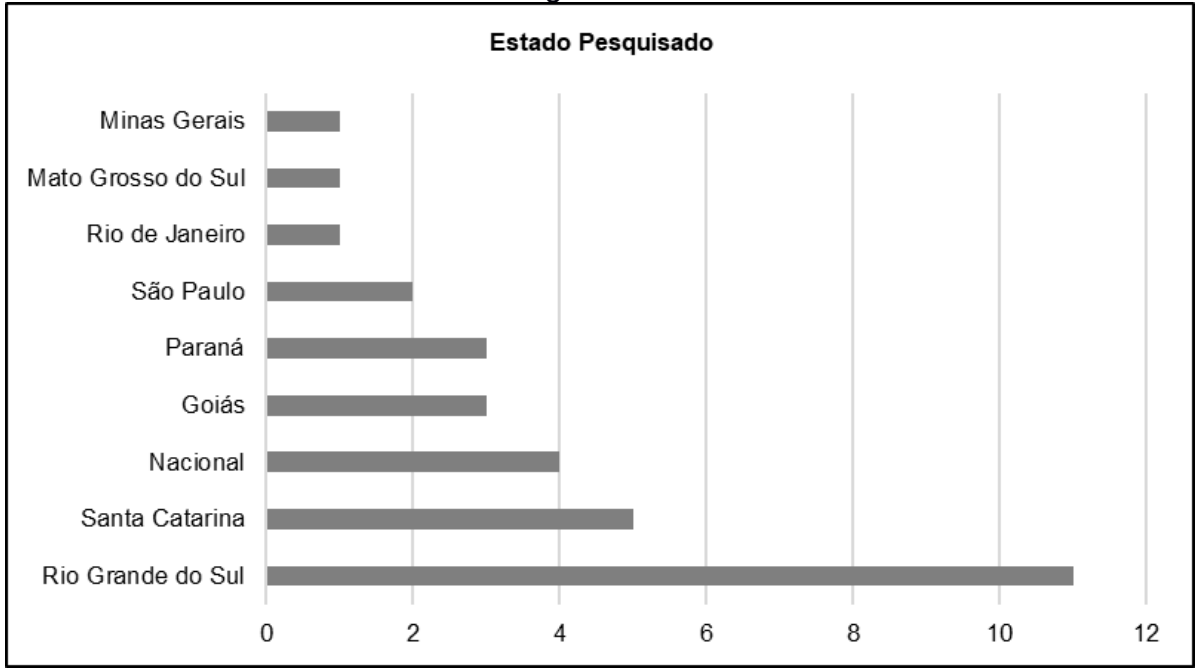

Fonte: Elaborado pelos autores a partir do Portal de Periódicos da CAPES - 2019.

Ao realizar as leituras bibliométricas nos resumos dos artigos, destacou-se que os motivos que aparecem com maior frequência sobre a permanência dos jovens nos espaços rurais são: abertura familiar; a proximidade das unidades familiares com centros urbanos; a possibilidade de uma renda maior; convivência com a comunidade; autonomia financeira; aprimoramento acadêmico; utilização de tecnologias no método produtivo; acesso as políticas públicas; a implantação de escolas de famílias agrícolas que possibilitam o acesso à educação; o matrimônio e o apego pela terra.

Para Brumer (2004), a migração é ocasionada em grande parte pela falta de oportunidade existente nos espaços rurais, principalmente para a inserção dos jovens independentemente dos pais. A autora acrescenta outros fatores que comprometem o processo sucessório como a invisibilidade do trabalho feminino dos jovens e das crianças, e o poder centrado no homem na chefia do estabelecimento e 
comercialização dos produtos, ocasionando a retirada paulatinamente da mulher no sistema produtivo familiar.

Contrariamente, os fatores que ocasionam o rompimento do processo sucessório em unidades produtivas familiares que aparecem com uma maior frequência nos trabalhos analisados estão: o poder patriarcal; a atividade penosa na atividade agrícola; baixas condições econômicas; a dificuldade do acesso à educação; a dificuldade ao acesso a serviços básicos e a falta de tecnologia.

Abramovay (2007), em seu estudo realizado com a juventude rural do Oeste de Santa Catarina, constata que existe uma contradição entre as opiniões dos jovens entrevistados sobre as exigências educacionais para o exercício da profissão agropecuária e a situação atual dos responsáveis pelas unidades produtivas familiares ou seus sucessores mais prováveis, com baixo nível de escolaridade.

Entre a tomada de decisão de ficar ou sair do estabelecimento, pelas características apresentadas acima, percebe-se um contraste nos motivos questionados pela juventude rural por tratar-se de pesquisas realizadas em diferentes regiões do país. As condições econômicas das unidades produtivas familiares dependem das atividades realizadas na propriedade e do mercado financeiro, bem como o preço do produto na localidade. É visível a existência de Políticas Públicas para a categoria, mas o seu alcance a determinadas regiões do Brasil acaba sendo ainda limitado. Quanto ao trabalho nos espaços rurais, estes apresentam uma nova configuração que estimulam os jovens a permanecerem nas propriedades.

Para Carneiro (2007), novas ocupações não agrícolas aparecem como alternativas viáveis para a juventude rural, principalmente nas atividades associadas a exploração do turismo, colaborando também com a mudança na remuneração, o direito a férias e finais de semana remunerados aparecem como um estímulo que afetaria os projetos de vida da juventude rural.

É importante destacar que além das questões sociais, o processo de sucessão rural depende dos fatores econômicos positivos das propriedades. Neste sentido, é necessário observar em quais cadeias produtivas e categorias sociopolíticas, a sucessão ocorre com maior frequência para que o jovem sucessor obtenha êxito em sua trajetória. No conjunto de 30 atividades e categorias classificadas nos artigos, a maioria não se declarou com 21 menções. Em seguida, o segundo destaque socioeconômico é a classe "Assentamentos da Reforma Agrária", com 4 menções nos artigos. Os demais aparecem somente uma vez como é o caso da agroindústria familiar; produção de leite; pecuária; feiras livres e cooperativa familiar. Presume-se que isso seja de fundamental importância para os possíveis sucessores, para que possam mapear em quais regiões uma determinada produção apresenta uma melhor saída para condições econômicas (Gráfico 3).

A partir da análise socioeconômica dessas atividades agropecuárias é possível visualizar quais cadeias produtivas são favoráveis ao processo sucessório. Vale ressaltar que os dados apresentam resultados de diferentes regiões do Brasil, portanto podem entrar em contradição.

No estudo de caso do assentamento rural no município de Campinas-SP, Albarotti e Martins (2016) puderam identificar que os membros da segunda geração familiar apresentaram uma forte ligação com o Assentamento. Entretanto, esse tipo de vínculo assume do modo ressignificado quando comparado aos valores, propósitos e projetos de vida da primeira geração. Os mais jovens estão buscando traçar novos caminhos para a história do assentamento com novas atribuições de trabalho rural, seja na elaboração de atividades não rurais dentro da propriedade e na busca de emprego na zona urbana sem deixá-lo.

Quanto a análise do processo sucessório na agroindústria familiar estudado por Wesz Junior (2009), aplicado na região de Missões-RS, aponta para fatores 
positivos contribuindo para que uma nova geração continue na propriedade. O mesmo ocorre com a empresa familiar do agronegócio na região Noroeste do Rio Grande do Sul permitindo a continuidade da empresa e manutenção familiar.

O mesmo acontece com a sucessão na produção leiteira na região de Lima Duarte-MG, onde Camilotto e Stock (2012), destacam que há uma necessidade maior de observação da realidade, principalmente para a institucionalização de políticas públicas para a atividade. Não foi possível a partir do resumo concluir se a atividade é viável ou não para ao processo sucessório, mas a autora acrescenta que não basta produzir eficientemente, o setor enfrenta deficiências que devem ser sanadas.

Para Matte, Spanevello e Andreatta (2015), o processo sucessório na atividade pecuária, aplicado ao município de Dom Pedrito-RS, constata que há um desestímulo por parte da juventude rural em continuar na atividade familiar. Porém, não relata se tal decisão é formada por fatores de decadência econômica; falta de aparatos tecnológicos ou assistência técnica.

O processo sucessório em Cooperativa Familiar trabalhado por Boessio (2015), na região do Triângulo Mineiro-MG, não apresentou dados sobre a concretização da transmissão geracional, mas esclareceu o papel da cooperativa em acompanhar o processo sucessório e propiciar maior rentabilidade para os sucessores.

Gráfico 3 - Atividades agrícolas presentes no trabalho sobre Sucessão Rural na Agricultura Familiar.

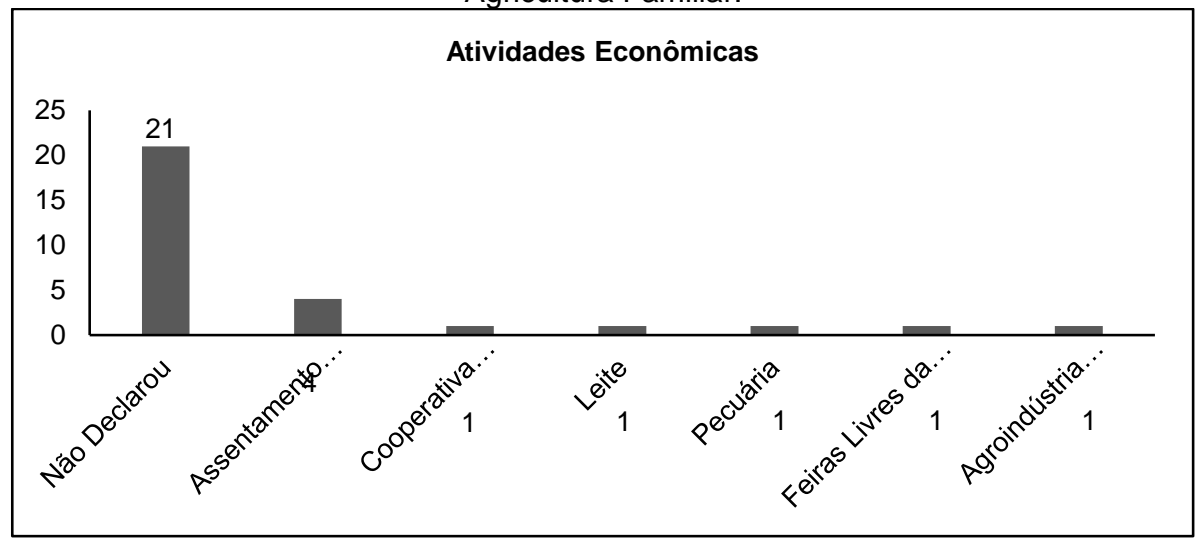

Fonte: Elaborado pelos autores a partir do Portal de Periódicos da CAPES - 2019.

Outro ponto importante desta investigação foi mapear em quais revistas estes trabalhos estavam sendo publicados. Na verdade, o primeiro colocado não é considerado periódico, é pelos Anais do Congresso da Sociedade Brasileira de Economia e Sociologia Rural (SOBER), com três publicações. Em seguida, com duas publicações, estão em destaque a Revista de Estudos Feministas, Revista de Economia e Sociologia Rural, Revista NERA, GEO UERJ, Ciência Rural, Política \& Trabalho e a revista científica argentina Mundo Agrário, de acordo com a Tabela 3. 
Tabela 3 - Principais periódicos onde os trabalhos foram publicados

\begin{tabular}{lr}
\hline Nome do Periódico & Número de Publicações \\
\hline Anais do Congresso da SOBER & 3 \\
Revista de Estudos Feministas & 2 \\
Revista de Economia e Sociologia Rural & 2 \\
Revista NERA & 2 \\
GEO UERJ & 2 \\
Ciência Rural & 2 \\
Política \& Trabalho & 2 \\
Mundo Agrário & 2 \\
Revista IDEAS & 1 \\
Agroalimentaria & 1 \\
Brazilian Journal of Development & 1 \\
Revista Latinoamericana de Ciencias Sociales, Ninez y Juventud & 1 \\
Revista de Ciências Humanas & 1 \\
Revista Brasileira de Estudos da População & 1 \\
História: Debates e Tendências & 1 \\
Revista da Universidade Vale do Rio Verde & 1 \\
Fronteiras & 29 \\
HOLOS & 1 \\
Revista de Estudos Sociais & 1 \\
Revista Paranaense de Desenvolvimento & 1 \\
\hline Total & 1 \\
\hline Fonte & 1 \\
\hline
\end{tabular}

Fonte: Elaborado pelos autores a partir do Portal de Periódicos da CAPES - 2019.

Outra vertente de investigação desse trabalho foi quanto a discussão a respeito da presença feminina no processo sucessório. Entre os trabalhos analisados, apenas 7 artigos discutem as questões de gênero no referido tema da pesquisa. Dentre os principais motivos apresentados que levam as mulheres a deixarem o protagonismo nos espaços rurais destacam-se: a escolha do homem para gerir a propriedade, dos mais jovens até os mais idosos e os valores culturais e matrimoniais. Nesse contexto, somente 2 artigos discutiram a respeito das políticas públicas e as responsabilidades femininas no campo. Conforme apresenta Castro e Barcellos (2015), se a categoria ser "jovem rural" no Brasil carrega uma posição hierárquica inferior, ser jovem rural e mulher representa uma situação de inferioridade hierárquica ainda maior.

Para Brumer (2004), a seletividade da migração ocorre com maior frequência pelas tradições culturais que priorizam o homem ao invés da mulher na execução de trabalhos agrícolas mais especializados, exigindo a utilização de técnicas e maquinários tecnológicos e pela chefia do estabelecimento, principalmente pela exclusão da mulher na herança. Tais fatores contribuem para uma maior presença masculina nos espaços rurais. 
Para Foguesatto et al. (2016), com o desinteresse dos jovens em administrar as atividades realizadas no campo, nos últimos anos o tema relacionado à sucessão geracional no meio rural familiar vem alcançando patamares elevados na academia, tornando-se cada vez mais objeto de estudo em diversas regiões do Brasil.

Conforme Castro (2009, p. 68), "as poucas ações que têm como público-alvo a juventude rural reforça a leitura de que se trata de um processo ainda pouco consolidado de visibilização dessa categoria social". Contrário o que é exposto pela autora, evidencia-se que a literatura e a legislação apontam para um número considerável de Políticas Públicas destinadas a agricultura familiar e juventude rural. Salienta-se que atualmente a juventude sai da invisibilidade para ser protagonista de suas ações, haja vista a criação do Decreto lei o no 8.736, de 3 de maio de 2016 (BRASIL, 2016).

Os fatores econômicos fazem parte dos vetores fundamentais na tomada de decisão entre o ficar e sair da propriedade. Aliado a esse diapasão, as atividades agrícolas aparecem como tendências de pesquisas na consolidação do processo sucessório e há poucos estudos que buscam demonstrar tal especificidade.

Conforme Carneiro (2007), as grandes cidades não têm exercido tanta atração aos jovens rurais como em décadas anteriores. Isso justifica-se pela pouca oferta de emprego e grande oferta de mão de obra no mercado de trabalho; pelas novas dinâmicas de atividades não agrícolas implementadas no campo; pela mobilidade que as motos proporcionam aos jovens transitar entre os dois espaços; e pelo acesso a tecnologias bens e serviços que a juventude rural vem demandando.

Uma chance de ascender socialmente o jovem rural é a educação profissionalizante desenvolvido pelas instituições públicas seja em ensino técnico ou nível superior. Redin (2017) afirma que o acesso à educação insere o jovem na aquisição de conhecimentos influenciando positivamente a transformação da unidade agrícola familiar e o próprio núcleo familiar o valoriza em especial no nível superior. Ultimamente com o interesse da juventude rural nas tecnologias de informação e comunicação e na educação o panorama social das comunidades rurais está mudando com perspectivas de desenvolvimento.

\section{CONSIDERAÇÕES FINAIS}

Ao longo do desenvolvimento do trabalho, foi possível perceber a diversidade de pesquisas em diferentes campos do conhecimento acerca do processo de sucessão rural na agricultura familiar. Apesar da grande abordagem acadêmica sobre o tema, alguns fatores de extrema importância deixam de ser trabalhados ou apresentam-se com pouca frequência nos resultados encontrados.

Independentemente da existência significativa de trabalhos sobre o processo de sucessão rural na agricultura familiar, destaca-se a ausência da discussão sobre as políticas públicas existentes para a juventude rural nas pesquisas analisadas. Notase também que há pouca discussão que focalizam outras temáticas emergentes no processo sucessório, como por exemplo, os fatores que ocasionam a permanência ou a saída do jovem dos espaços rurais, as relações de gênero e as demandas da juventude rural.

Cabe ressaltar que embora haja uma consolidação das políticas públicas destinadas a agricultura familiar e juventude rural em caráter nacional, essa categoria vem sendo pouco discutida nos trabalhos acadêmicos analisados. Isso demonstra uma limitação que precisa ser bem explorada e fundamentada pelas propostas de pesquisa dos programas de pós-graduação, bem como levar ao conhecimento dessas ações ao cidadão beneficiário dessas ações. 
Constata-se neste estudo uma oposição às pesquisas analisadas, pois grande parte dos trabalhos trazem a juventude rural como um ator invisível perante as políticas públicas e ações governamentais, e o que realmente percebe-se é que as políticas existem, mas o seu alcance acaba sendo limitado a determinadas regiões do Brasil. Nota-se também que grande parte das publicações estão sendo mais estudadas na região Sul Brasileira, mais especificamente no Estado do Rio Grande do Sul.

Outro fator importante a ser destacado entre as pesquisas analisadas consiste na limitação dos trabalhos quanto ao processo de sucessão rural na agricultura familiar em diferentes cadeias produtivas porque a maioria das publicações não declararam suas atividades econômicas. Esse tipo de análise se faz necessária para a observação de quais produtos teriam uma maior viabilidade socioeconômica para determinada região, o que poderia contribuir para a permanências dos jovens na atividade ou uma possível diversificação na cultura agrícola, que poderia ser um fator primordial para a transmissão geracional da propriedade.

Apesar da produção acadêmica sobre sucessão rural e agricultura familiar ser densa, há temas ainda que podem ser mais explorados pelas diferentes áreas do conhecimento com melhor distinção regional para sucessão na agricultura familiar e a inserção dos jovens na transmissão geracional é uma perspectiva em aberto para novas investigações.

Trabalhos futuros poderão vir analisar as especificidades que estimulam ou desestimulam o processo sucessório. As cadeias produtivas, os valores de mercados pagos aos produtores rurais, as dificuldades na produção ou dificuldade de se manter no campo são vetores que deverão ser estudados em regiões específicas para que se possa ter resultados mais detalhados para as possíveis soluções para os problemas.

\section{REFERÊNCIAS}

ABRAMOVAY, R. Juventude e agricultura familiar: desafios dos novos padrões sucessórios. Brasília: UNESCO, 1998. 101 p.

ABRAMOVAY, R.; SILVESTRO, M. L.; MELLO, M. A. de; DORIGON, C.; BALDISSERA, I. T. Agricultura familiar e sucessão profissional: novos desafios. In: CONGRESSO BRASILEIRO DE ECONOMIA E SOCIOLOGIA RURAL, 39, 2007, Recife, Anais... Brasília: SOBER, 2007. 10 p. Disponível em: http://www.gp.usp.br/files/denru_sucessao.pdf. Acesso em: 19 jun. 2017.

ALBAROTI, A. E.; MARTINS, R. C. Configurações contemporâneas dos assentamentos rurais de reforma agrária: o surgimento de novas gerações e a construção de novos projetos de vida. Política \& Trabalho, João Pessoa, v. 1, n. 45, p. 213-232, 2016.

AQUINO, J. R.; SCHNEIDER, S. O Pronaf e o desenvolvimento rural brasileiro: avanços, contradições e desafios para o futuro. In: GRISA, C.; SCHNEIDER, S. Políticas públicas de desenvolvimento rural no Brasil. Porto Alegre: Editora da UFRGS, 2015, p. 53-82.

BOESSIO, A. T. Jovens rurais e processos de sucessão: em análise uma cooperativa agropecuária no Triângulo Mineiro. 2015. 183 f. Dissertação (Mestrado 
em Extensão Rural). Programa de Pós-Graduação em Extensão Rural. Universidade Federal de Viçosa.

BRASIL. Senado Federal. Lei no 11.326, de 24 de julho de 2006. Estabelece as diretrizes para a formulação da Política Nacional da Agricultura Familiar e Empreendimentos Familiares Rurais. Diário Oficial da União, Brasília, DF, 24 de jul. de 2006. Disponível em: http://www.planalto.gov.br/ccivil_03/_Ato20042006/2006/Lei/L11326.htm. Acesso em: 15 maio. 2019.

BRASIL. Decreto n. 8.736, de 3 de maio de 2016. Institui o Plano Nacional de Juventude e Sucessão Rural. Diário Oficial da União; Brasília, 3 maio. 2016. Disponível em: http://www.planalto.gov.br/ccivil_03/_ato20152018/2016/decreto/D8736.htm. Acesso em: 08 de maio. 2017.

BRASIL. Ministério do Desenvolvimento Agrário. Saf - Crédito Rural. 2017. Disponível em: http://www.mda.gov.br/sitemda/secretaria/saf-creditorural/sobre-oprograma. Acesso em: 08 maio. 2017.

BRUMER, A. Gênero e agricultura: A situação da mulher na agricultura do Rio Grande do Sul. Revista Estudos Feministas, Florianópolis, v. 12, n. 1, p. 205-227, jan/abr. 2004.

CAMILOTTO, A. H. G.; STOCK, L. A. Condicionantes do processo de sucessão familiar entre produtores de leite da zona da mata mineira. Rev. Inst. Latic. "Cândido Tostes", Juiz de Fora, v. 67, n. 386, p. 91-92, maio./jun 2012.

CARNEIRO, M. J. Juventude e novas mentalidades no cenário rural. In: CARNEIRO, M. J.; CASTRO, E. G. (Orgs.). Juventude Rural em perspectiva. Rio de Janeiro, Mauad X, 2007.

CASTRO, E. G.; BARCELLOS, S. B. Políticas Públicas para a Juventude Rural Brasileira. In: GRISA, C.; SCHNEIDER, S. Políticas públicas de desenvolvimento rural no Brasil. Porto Alegre: Editora da UFRGS, 2015, p. 549-570.

DIAS, M. M. Glossário de Termos utilizados em Desenvolvimento Rural. 1 ed. Rio de Janeiro: Instituto Souza Cruz. 2000. 109 p.

FERREIRA, N. S. O. As pesquisas denominadas "estado da arte". Educação \& Sociedade, Campinas, ano XXIII, n 79, p. 257-272, ago. 2002.

FLORES, M. Apresentação. In: ABRAMOVAY, R. Juventude e agricultura familiar: desafios dos novos padrões sucessórios. Brasília: UNESCO, 1998. p. 9-11.

FOGUESATTO, C. R.; LAGO, A.; SPANEVELLO, R. M.; ANDREATTA, T.; OLIVEIRA, S. V. A sucessão geracional na agricultura familiar sob a óptica do jovem migrante. In: ENCONTRO DE ECONOMIA GAÚCHA, 7, 2014, Porto Alegre. Anais... Porto Alegre: PUCRS, 2014.

GIL, A. C. Métodos e técnicas de pesquisa social. São Paulo: Atlas, 2008. 200 p.

GRIS, V. G. C.; LAGO, S. M. S.; BRANDALISE, L. T. Sucessão na Agricultura Familiar: produção científica brasileira na área de administração pública e de empresas, 
ciências contábeis e turismo (2004-2016). Extensão Rural, Santa Maria, v.24, n.4, p. 7-30, out./dez. 2017. Disponível em: https://periodicos.ufsm.br/extensaorural/article/view/29816/pdf. Acesso em: 23 jun. 2019.

GRISA, C.; SCHNEIDER, S. Três gerações de políticas públicas para a agricultura familiar e formas de interpretação entre sociedade e Estado no Brasil. Revista de Economia e Sociologia Rural, Piracicaba, v. 52, p.125-146, 2014.

KRUGER, S. D.; SILVA, M. A. L.; MORES, G. V.; PETRI, S. M. Fatores Determinantes para a sucessão familiar em estabelecimentos rurais da Região Oeste de Santa Catarina. Extensão Rural, Santa Maria, v.25, n.4, p. 57-70, out./dez. 2018. Disponível e,: https://periodicos.ufsm.br/extensaorural/article/view/30576/pdf. Acesso em: 23 jun. 2019.

MATTE, A.; SPANEVELLO, R. M.; ANDREATTA, T. Perspectivas de sucessão em propriedades de pecuária familiar no município de Dom Pedrito-RS. Rev. Holos, Natal, Ano 31, vol. 1, p. 144-159, 2015.

REDIN, E. Políticas educacionais e juventude rural no Ensino Superior. Educar em Revista, Curitiba, n. 63, p. 237-252, jan./mar. 2017. Disponível em: http://www.scielo.br/pdf/er/n63/1984-0411-er-63-00237.pdf. Acesso em: 23 jun. 2019.

SPANEVELLO, R. M. A dinâmica sucessória na agricultura familiar. 2008. 223 p. Tese (Doutorado em Desenvolvimento Rural) - Programa de Pós-Graduação em Desenvolvimento Rural, Universidade Federal do Rio Grande do Sul.

STROPASOLAS, V. L. Um marco reflexivo para a inserção social da juventude rural. In: CARNEIRO, M. J; CASTRO, E. G de. Juventude rural em perspectiva. Rio de Janeiro: Mauad X, 2007.

STROPASOLAS, V. L. Os desafios da sucessão geracional na agricultura familiar. Agriculturas: experiências em agroecologia. Rio de Janeiro, v. 8, n. I, p. 26-29, março de 2011.

WANDERLEY, M. de N. B. "Agricultura familiar e campesinato: rupturas e continuidade." Estudos Sociedade e Agricultura. Rio de Janeiro, v. 11, n. 21, p. $42-$ 61, out. 2003.

WANDERLEY, M. N. B. Jovens rurais de pequenos municípios de Pernambuco: que sonhos para futuro? In: CARNEIRO, M. J.; CASTRO, E. G. (Org.) Juventude Rural em Perspectiva. Rio de Janeiro: Mauad, 2007.

WESZ JUNIOR, V. J. Novas configurações no meio rural brasileiro: uma análise a partir das propriedades com agroindústria familiar. Agroalimentaria, Caracas, v. 15, n. 28, p. 25-34, jun. 2009. 